\title{
ARTICLE
}

\section{Polarization-modulation infrared reflection absorption spectroscopy studies of gas-metal interactions}

\author{
Katia Weulersse-Mouturat ${ }^{*}$, Bertrand Baubet, Lilian Berlu and Benoît Reneaume
}

CEA, 21120 Is-sur-Tille, France

\begin{abstract}
A Polarization-Modulation InfraRed Reflection Absorption Spectroscopy (PM-IRRAS) device has been recently acquired by CEA (Commissariat à l'Energie Atomique) to improve knowledge on gas-metal interactions mechanisms. PM-IRRAS technique has capability to give simultaneous in situ new insights on gas phase and surface evolutions during heterogeneous reactions. As a preliminary work, the oxidation of ethyl alcohol on copper has been investigated. The surface species can be clearly identified and evolution versus temperature shows the progressive oxidation towards surface bridged acetates. Next experiments will be soon performed in a glovebox with a specifically designed reaction cell to investigate interactions between metal oxide and gases, firstly with cerium and then with actinides.
\end{abstract}

Keywords: gas-metal interactions; catalysis; corrosion; infrared spectroscopy; PM-IRRAS; copper; cerium; actinides

\section{Introduction}

Gas-metal interactions are of great interest in the area of heterogeneous catalysis as well as in the area of corrosion. The simultaneous knowledge of gaseous atmosphere composition and surface interactions is of primary importance for a better understanding of the mechanisms involved in catalysis or corrosion.

PM-IRRAS measurements allow the in situ analysis of the surface and of the gas phase separately but simultaneously.

\section{Experimental section}

\subsection{PM-IRRAS technique}

PM-IRRAS spectroscopy was developed in the eighties' [1-3] for its surface sensitivity and was then used to investigate ultrathin layers characterization on metallic surfaces.

PM-IRRAS technique uses the two polarizations generated by the photo-elastic modulator (PEM). The reflection of a s-polarized beam (reflectivity Rs, polarization perpendicular to the plane of incidence) on a metal leads to the cancellation of the surface electric field. A spectrum acquired with a s-polarization will then include only gas-phase absorptions, whereas the one resulting from a p-polarization (reflectivity $\mathrm{Rp}$, polarization parallel to the plane of incidence) will contains gas phase and surface information. The use of

*Corresponding author. Email: katia.weulersse@cea.fr these two polarizations permit to analyse, in situ, the surface ("Rp-Rs" signal) and the gas phase ("Rp+Rs" signal) separately but simultaneously.

PM-IRRAS is rarely used to obtain information on gas phase as this technique is primarily designed for surface analysis. Rupprechter et al. [4, 5] used this technique, from ultra-high vacuum to atmospheric pressure, for both surface and gas analysis in order to give new insights on reaction pathways for model catalysts.

\subsection{PM-IRRAS device}

CEA recently acquired a made-to-measure PM-IRRAS device composed of a Thermo iS50 Fourier transform infrared spectrometer equipped with a $\mathrm{ZnSe}$ polarizer and a photo-elastic modulator (PEM-100 from HINDS Instruments) to investigate the surface / atmosphere composition relationship on metallic materials. The PM-IRRAS measurements are performed in specular reflection mode under grazing incidence $\left(10^{\circ}\right.$ relatively to the surface) (Figure 1).

The specific aim of this PM-IRRAS device is to perform experiments in a glovebox on actinide oxide samples exposed to gaseous environments.

\subsection{Preliminary experiments}

First, aluminum samples were analyzed in order to verify that the device allows to obtain high signal/noise ratios for the Al-O stretching peak of native alumina on aluminum.

Then, qualification of the PM-IRRAS device out of 
the glovebox was done by studying of the oxidation of ethyl alcohol on as received polycrystalline copper sample $\left(20 \times 20 \times 2 \mathrm{~mm}^{3}\right)$ (half hard sample supplied by Goodfellow with a $99.9 \%$ purity) with focus on the surface interactions. This system has been often described in the literature [6-8], which permits comparison with the results.

A copper sample was simply immersed in ethyl alcohol. The interaction was then studied under air, at $298 \mathrm{~K}$ or higher temperatures, in a reaction cell equipped with $\mathrm{ZnSe}$ windows.

\section{Results and discussion}

Under air, at $298 \mathrm{~K}$, the adsorption of ethyl alcohol on copper superficial oxide layer leads (Figure 2) to the formation of surface ethoxy species which can be clearly identified as stretching $\mathrm{CH}_{3}$ asymmetric and $\mathrm{CH}_{2}$

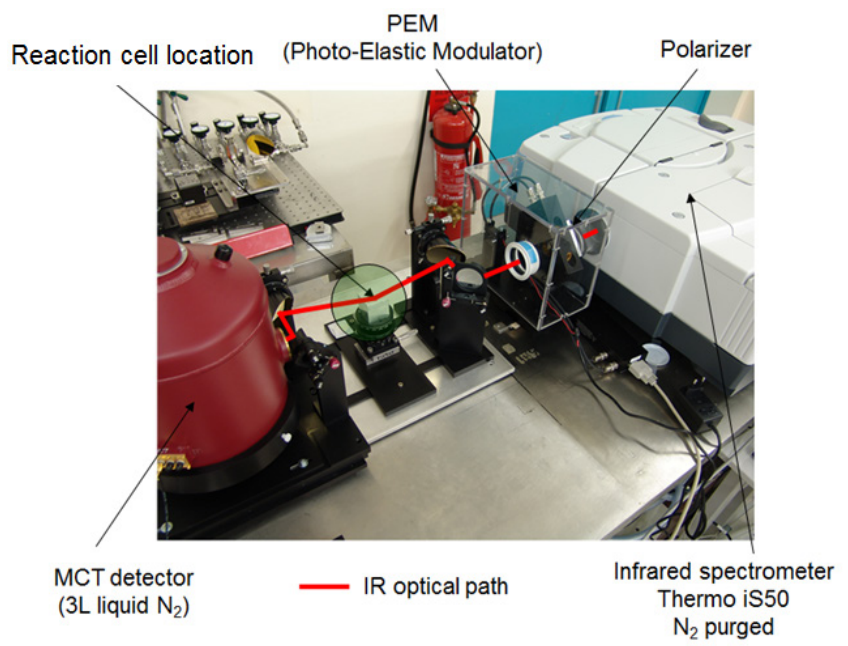

Figure 1. Photograph of the PM-IRRAS device out of the glovebox.

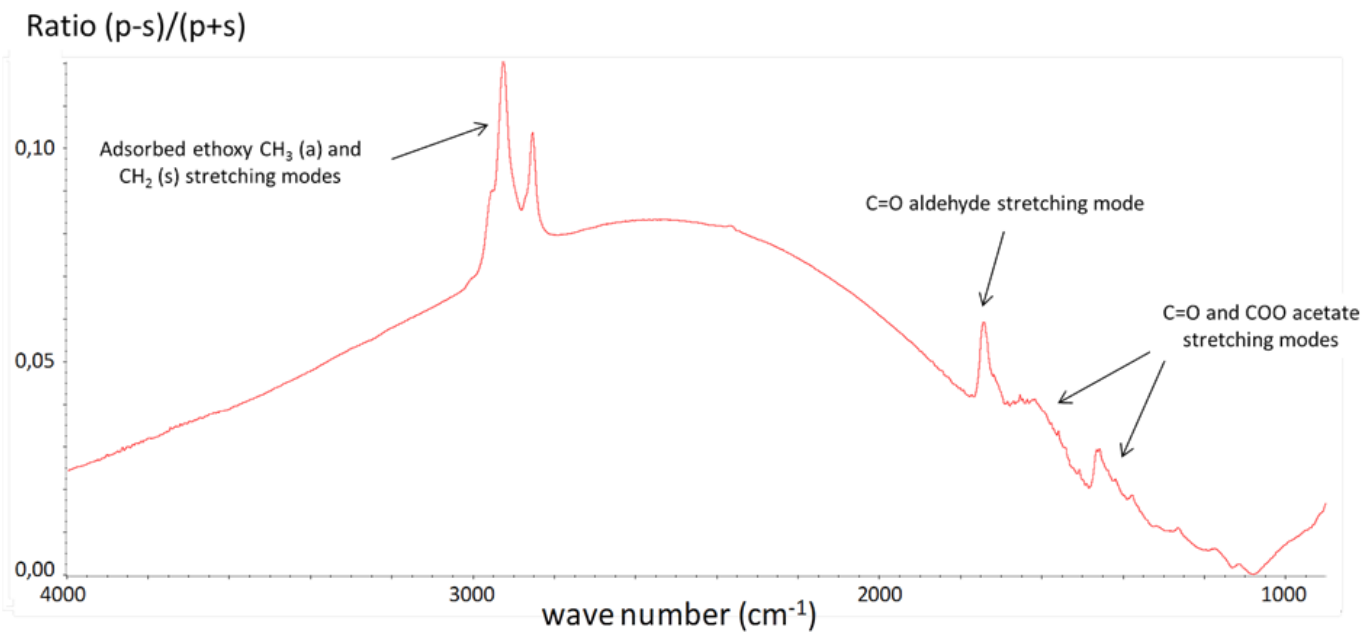

Figure 2. Spectrum of copper exposed to ethyl alcohol at $298 \mathrm{~K}$ (PEM set at $\left.2000 \mathrm{~cm}^{-1}\right)$.

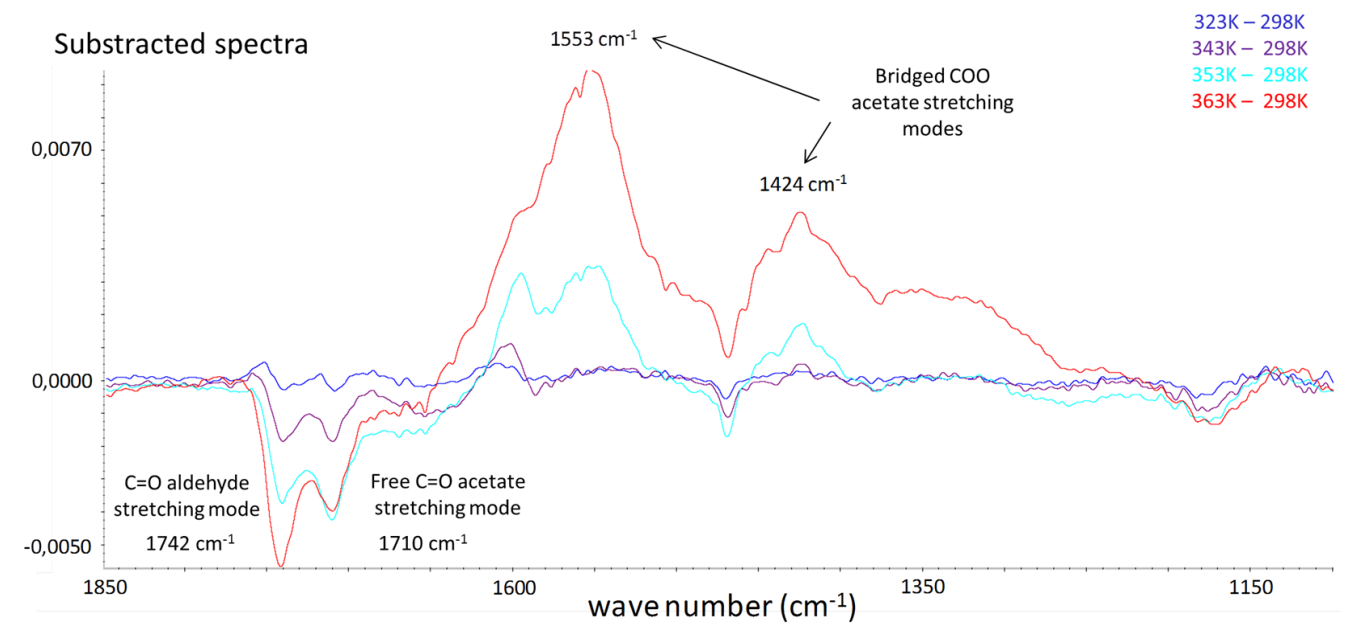

Figure 3. Subtracted spectra for different temperatures (Spectrum at $298 \mathrm{~K}$ has been subtracted from the spectra at 323, 343, 353 and $363 \mathrm{~K}$ to study the influence of the temperature). 
symmetric modes at $2926 \mathrm{~cm}^{-1}$ and $2854 \mathrm{~cm}^{-1}$ respectively [8]. Ethoxy gives also weak bands between $1400 \mathrm{~cm}^{-1}$ and $1000 \mathrm{~cm}^{-1}$. Other contributions at 1742 $\mathrm{cm}^{-1}, 1553 \mathrm{~cm}^{-1}$ and $1424 \mathrm{~cm}^{-1}$ correspond very probably to $\mathrm{CO}$ aldehyde and $\mathrm{COO}$ carboxylate stretching vibrations which indicates an oxidation of the ethoxy species [9].

The evolution of surface species versus temperature is studied on the basis of difference spectra between several temperatures (in the 323-363 K range) and 298 $\mathrm{K}$ (Figure 3). The increase of temperature accelerates the oxidation rate and raises the proportion of formed bridged acetate.

No significant evolution of the gas phase composition has been noticed. This was probably due to concentration changes in the gas that were too low to be measured during this experiment.

\section{Conclusion}

PM-IRRAS is a very powerful technique for studying gas-metal interactions. The oxidation of ethyl alcohol on copper has been here investigated. The surface species can be clearly identified and evolution versus temperature shows the progressive oxidation towards surface bridged acetates. This study permitted the qualification of the PM-IRRAS device before performing experiments in a glovebox environment.

\section{Outlook}

After having been qualified thanks to preliminary experiments on copper, the PM-IRRAS device has been put into a glovebox (Figures 4 and 5) to be able to study gas interactions with specific metals such as cerium or actinides which need to be handled in glovebox under inert atmosphere. The spectrometer and the polarizer-PEM system have been set outside the glovebox.

As far as we knew, this PM-IRRAS is the first to be placed in a glove box and dedicated to actinide studies. This kind of device should represent a significant advance in the ability to characterize and understand the adsorption and reaction of gaseous molecules with the surface of actinides. But before that, certain difficulties related to the specificities of the environment and the work in glove box must be overcome to allow such studies. So preliminary experiments had to be done.

For these experiments, a new reaction cell with windows perpendicular to the IR incident and reflected beams has been home-developed (Figure 6). This cell permits to work with controlled atmosphere, pressure and temperature.

This PM-IRRAS device environment development will enable simultaneous and rigorous analysis of gas and surface under various pressures and temperatures.

New experiments on copper inside the glovebox have confirmed the capability and sensitivity of the technique in this environment despite vacuum pump vibrations and an additional window. The glovebox limits the water vapor infrared contribution.

Next studies will consist in exploring interactions between cerium inflammable samples and gases.

The specific aim of the PM-IRRAS device is then to perform experiments on actinide oxide layer on flat metallic samples exposed to gaseous environments.

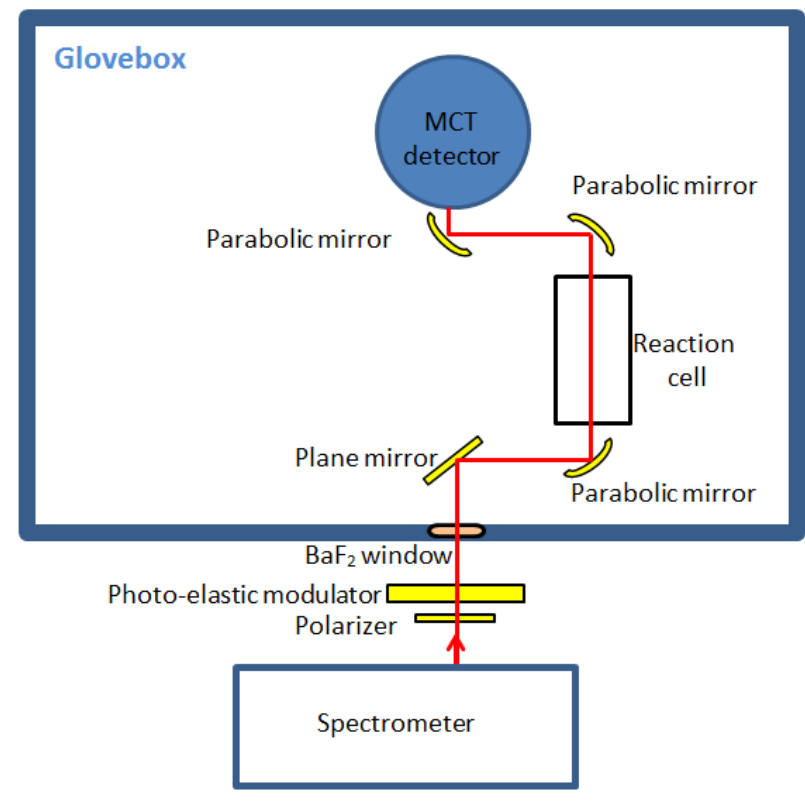

Figure 4. Layout of the PM-IRRAS device after its introduction in a glovebox.

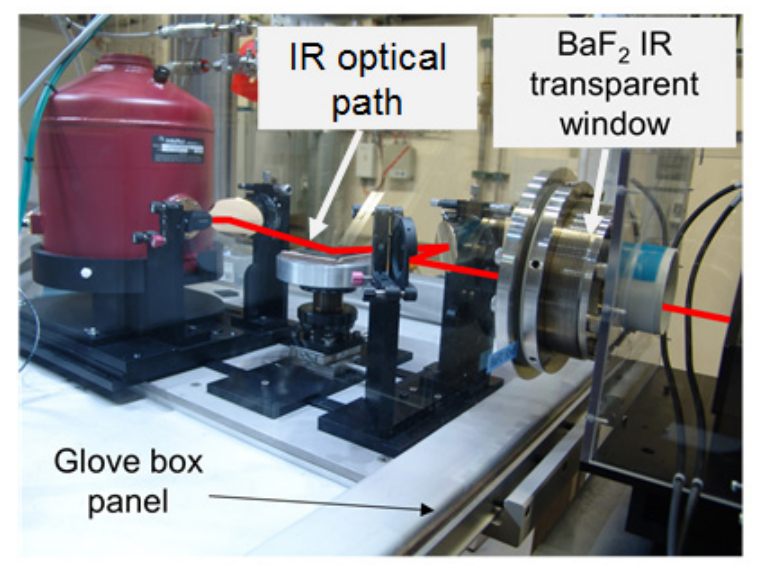

Figure 5. Photograph of the PM-IRRAS device after its introduction in a glovebox. 


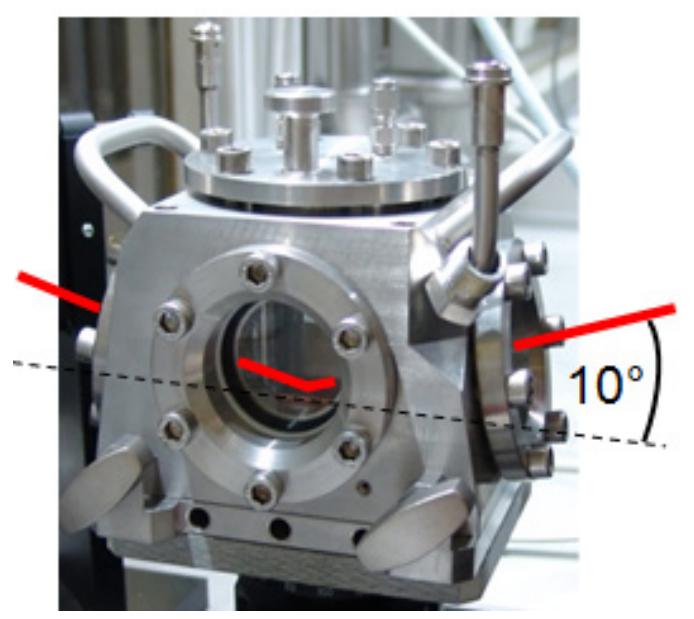

Figure 6. Photograph of the new home-designed reaction cell.

\section{References}

[1] L.A. Nafie and D.W. Vidrine, Double modulation Fourier transform spectroscopy, Fourier transform infrared spectroscopy, Chap. 3, Vol. 3, Academic Press, New-York, (1982), pp.83-123, ISBN 0-12-254103-0.

[2] W.G. Golden, Fourier transform infrared reflection-absorption spectroscopy, Fourier transform infrared spectroscopy, Chap. 8, Vol. 4 Academic Press, New-York, (1985), pp.315-344, ISBN 0-12-254104-9.

[3] T. Buffeteau, Etude des propriétés optiques de couches minces dans l'infrarouge., Développement de la spectroscopie F.T.I.R de surfaces et films ultraminces par modulation de polarisation, $\mathrm{PhD}$ thesis report, Bordeaux University (1988). [in French].

[4] G. Rupprechter, Sum Frequency Generation and Polarization-Modulation Infrared Reflection Absorption Spectroscopy of functioning model catalysts from ultrahigh vacuum to ambient pressure, Advances in Catalysis 51 (2007), pp 133-263.

[5] G. Rupprechter and C. Weilach, Spectroscopic studies of surface-gas interactions and catalyst restructuring at ambient pressure: mind the gap, $J$. Phys.: Condens. Matter 20 (2008), 184019, pp. 3-17.

[6] I.E. Wachs and R.J. Madix, The oxidation of ethanol on $\mathrm{Cu}(110)$ and $\operatorname{Ag}(110)$ catalysts, Applications of Surface Science 1 (1978), pp. 303-328.

[7] B.A. Sexton, Surface vibrations of adsorbed intermediates in the reaction of alcohols with Cu(100), Surface Science 88 (1979), pp. 299-318.

[8] J.P. Camplin and E.M. McCash, A RAIRS study of methoxy and ethoxy on oxidised $\mathrm{Cu}(100)$, Surface Science 360 (1996), pp. 229-241.

[9] C.-C. Chuang, W.-C. Wu, M.-X. Lee and J.-L. Lin, Adsorption and photochemistry of $\mathrm{CH}_{3} \mathrm{CN}$ and $\mathrm{CH}_{3} \mathrm{CONH}_{2}$ on powdered $\mathrm{TiO}_{2}$, Phys. Chem. Chem. Phys. 2 (2000), pp. 3877-3882. 